\title{
Roles of miR-138 and ISG15 in oral squamous cell carcinoma
}

\author{
QIMEI ZHANG $^{1}$, YI HE ${ }^{2}$, MINHAI NIE ${ }^{1}$ and WEI CAI ${ }^{1}$ \\ Departments of ${ }^{1}$ Oral Medicine and ${ }^{2}$ Urinary Surgery, Affiliated Hospital of Luzhou Medical College, \\ Luzhou, Sichuan 646000, P.R. China
}

Received September 6, 2015; Accepted December 9, 2016

DOI: $10.3892 / \mathrm{etm} .2017 .4720$

\begin{abstract}
The aim of the present study was to investigate the roles of microRNA (miR)-138 and interferon-stimulated gene 15 (ISG15) in patients with oral squamous cell carcinoma (OSCC). miR-138 and ISG15 expression in cancer tissues was detected, and the influence on proliferation, migration and invasion of OSCC cell lines was assessed. Reverse transcription-quantitative polymerase chain reaction was performed to analyze the expression of miR-138 and ISG15 in resected cancer tissues and pericancerous tissues harvested from patients with OSCC. The protein level of ISG15 was determined via western blot analysis. The constructed pGCMV/EGFP/miR-138 plasmid was transfected into CAL27 and SCC-15 OSCC cell lines via a liposome method to upregulate miR-138 expression. The transfection efficiency was determined based on miR-138 expression levels, and changes in proliferation, migration and invasion were subsequently compared with those in untransfected cells. The expression of ISG15 mRNA and protein was also detected in OSCC cells. miR-138 was significantly downregulated $(\mathrm{P}<0.05)$ in cancer tissues compared with adjacent normal tissues in patients with OSCC, whereas ISG15 mRNA expression levels were significantly higher in pericancerous tissues $(\mathrm{P}<0.05)$. ISG15 protein levels were also significantly higher in pericancerous tissues $(\mathrm{P}<0.05)$. ISG15 protein and mRNA levels were significantly decreased in the transfected cells compared with the untransfected cells, which indicated that miR-138 overexpression inhibited ISG15 expression. Additionally, the invasion, migration and proliferation abilities of successfully transfected CAL27 and SCC-15 cells were significantly decreased compared with the untransfected cells $(\mathrm{P}<0.05)$. The results of the present study suggest that miR-138 functions as a tumor-suppressive miR and serves an important role in OSCC via regulating ISG15 expression. These findings
\end{abstract}

Correspondence to: Professor Minhai Nie, Department of Oral Medicine, Affiliated Hospital of Luzhou Medical College, 25 Taiping Street, Yangjiang, Luzhou, Sichuan 646000, P.R. China

E-mail: ziu001@163.com

Key words: microRNA-138, oral squamous cell carcinoma, interferon-stimulated gene 15 suggest that miR-138 is able to inhibit the proliferation, migration and invasion of OSCC cell lines.

\section{Introduction}

Oral cancer is the sixth most prevalent form of cancer, with oral squamous cell carcinomas (OSCC) having the highest morbidity of all head and neck cancers (1). Patients with OSCC typically have a poor prognosis due to its invasion and migration capabilities, and the five-year survival rate is $<50 \%$ (1). The underlying mechanisms of OSCC development were complex and dependent on regulation at the DNA, transcriptional, post-transcriptional and protein levels (2). microRNAs (miRNAs or miRs) are a class of 20-25 nucleotide endogenous non-coding RNAs (3). miRNAs are able to regulate various biological processes, such as metabolism, differentiation, proliferation and apoptosis (4). Numerous studies have demonstrated that miRNAs are able to serve as oncogenes and tumor suppressors, and participate in the development of cancers via regulating tumor cell proliferation, differentiation, apoptosis and other biological processes by degrading mRNA or inhibiting translation of oncogenes or tumor suppressor genes $(5,6)$. miRNAs have been demonstrated to be associated with the development and progression of cancers, and they may have potential applications as biomarkers for the diagnosis of various cancers (7). miR-138 has previously been demonstrated to serve as a tumor suppressor gene in nasopharyngeal cancer (8), liver cancer (9) and ovarian cancer (10); however, the roles of miR-138 in the development and progression of OSCC remain to be elucidated.

The ubiquitin proteasome pathway (UPP) is an important mechanism underlying intracellular protein degradation (11). Following ubiquitination, the modified proteins will be degraded by proteasome (11). Interferon-stimulated gene 15 (ISG15) is a small protein with a low molecular weight induced by the expression of type I interferon, which is an upstream regulator in the UPP pathway. A previous study revealed that UPP participates widely in cell cycle regulation and apoptosis (12). Desai et al (13) demonstrated that the overexpression of ISG15 in cancer cells is able to negatively regulate ubiquitin-26S UPP via inhibiting the poly-ubiquitination of target proteins. ISG15 was also demonstrated to be upregulated in breast cancer, ovarian cancer and prostate cancer cells, whereas the corresponding ubiquitinated proteins were downregulated (13). ISG15 was also upregulated in 
cancer tissues from patients with pancreatic, endometrial and bladder cancer compared with pericancerous tissues (14). Andersen et al (15) demonstrated that ISG15 was highly expressed in bladder cancer tissues and that expression levels were significantly associated with the malignant grading. In the present study the expression and roles of miR-138 and ISG15 were investigated in patients with OSCC along with bioinformatic predictions.

\section{Materials and methods}

Collection of cancer tissues. The present study included a total of 20 patients with OSCC who underwent surgical resection at the Affiliated Hospital of Luzhou Medical College (Luzhou, China) between December 2013 and December 2014. Patients had an average age of 56 years, and there were 12 males and 8 females. Prior to surgery, all patients were diagnosed with OSCC by pathologists. Patients received no radiotherapy, chemotherapy or other adjuvant therapies. Cancer tissues and pericancerous tissues were frozen with liquid nitrogen and stored at $-80^{\circ} \mathrm{C}$ within $10 \mathrm{~min}$ of being harvested. Prior written and informed consent was obtained from all patients and the study was approved by the Ethics Review Board of the Affiliated Hospital of Luzhou Medical College.

Bioinformatics prediction. Targetscan (www.targetscan.org) was used to analyze the miRNA binding sites in the ISG15 mRNA 3'-untranslated region (UTR). The candidate miRNAs were listed based on the scores assigned by Targetscan. Combined with the results of a literature review, miR-138 was selected for use in the present study.

Cell culture and transfection. Two OSCC cell lines, CAL27 and SCC-15 (American Type Culture Collection, Manassas, VA, USA), were cultured in Dulbecco's modified Eagle's medium (DMEM; Hyclone; GE Healthcare Life Sciences, Logan, UT, USA) containing L-glucose (Hyclone; GE Healthcare Life Sciences) and 10\% fetal bovine serum (Beyotime Institute of Biotechnology, Haimen, China) (FBS). Lipofectamine 2000 (Invitrogen; Thermo Fisher Scientific, Inc., Waltham, MA, USA) was used to transfect CAL27 and SCC-15 cells according to the manufacture's protocol. At $24 \mathrm{~h}$ prior to transfection, $2 \times 10^{5} \log$-growth cells were seeded in 24 -well plates. Cells were divided into three groups based on their transfection status: i) miR-138 group (transfected with pGCMV/EGFP/miR-138 vector); ii) Neg-miR-138 group (Mock); and iii) control group (Blank). Lipofectamine 2000 (Invitrogen; Thermo Fisher Scientific, Inc.) was used for transfection according to the manufacturer's protocol. A total of $2 \mu \mathrm{g}$ pGCMV/EGFP/miR-138 vector and $1 \mu \mathrm{l}$ Lipofectamine 2000 was added into Eppendorf tubes containing $50 \mu \mathrm{l}$ Opti Memi medium. The tube was left to stand for $5 \mathrm{~min}$ at room temperature, mixed together and subsequently left to stand for a further $20 \mathrm{~min}$ at room temperature. When cell density reached $\sim 60 \%$, cells were added to 24-well plates. The H-DMEM containing $10 \%$ FBS was replaced $6 \mathrm{~h}$ post-transfection and cells were harvested at $48 \mathrm{~h}$ post-transfection. Reverse transcription-quantitative polymerase chain reaction (RT-qPCR) was used to detect the expression of miR-138 in the collected cells to determine the transfection efficiency.
RNA extraction and RT. Total RNA was isolated from tissues using $1 \mathrm{ml}$ TRIzol (Invitrogen; Thermo Fisher Scientific, Inc.) reagent per $100 \mathrm{mg}$, according to the manufacturer's protocol. For transfected CAL27 and SCC- 15 cells, $2 \times 10^{5}$ cells were treated with $1 \mathrm{ml}$ TRIzol reagent. The phenol-chloroform method was used to extract total RNA as described previously (16). RNA integrity was verified via gel electrophoresis using $2 \%$ agarose gel, and the purity of RNA was detected using a spectrophotometer. cDNA was synthesized from total RNA via reverse transcription with the Reverse Transcription System (Takara Biotechnology Co., Ltd., Dalian, China) and stored at $-20^{\circ} \mathrm{C}$. The reverse transcription system included: $6 \mu \mathrm{lmiRNA}$ template, $10 \mu 12 \mathrm{X}$ miRNA Reaction Buffer Mix, $2 \mu 10.1 \%$ bovine serum albumin (BSA) and $2 \mu \mathrm{lmiRNA}$ PrimeScript RT Enzyme Mixture (all Takara Biotechnology Co., Ltd.) to give a total reaction volume of $20 \mu \mathrm{l}$. The reaction was performed at $37^{\circ} \mathrm{C}$ for $60 \mathrm{~min}$ with PolyA primer. A total of $100 \mu \mathrm{l}$ RNase free $\mathrm{H}_{2} \mathrm{O}$ was subsequently added and $2 \mu \mathrm{l}$ was removed and used for quantitative detection.

Detection of miR-138 by RT-qPCR. The Takara PrimeScript kit (Takara Biotechnology Co., Ltd.) was used for the RT-qPCR, and miR-138 was detected using SYBR green RT-qPCR with U6 as an internal reference. The primers for miR-138 were forward 5'-GACCCAGATTCCACCATAT-3' and reverse (Uni-miR qPCR Primer) 5'-CAGTGCAGGGTCCGAGGT-3'. The reaction system included 12.5 $\mu \mathrm{l}$ SYBR Premix Ex Taq (Takara Biotechnology Co., Ltd.), $1 \mu 1$ PCR Forward Primer (Sangon Biotech Co., Ltd., Shanghai, China), $1 \mu$ l Uni-miR qPCR Primer (Takara Biotechnology Co., Ltd.), $2 \mu$ l template and $8 \mu \mathrm{l}$ double distilled (dd) $\mathrm{H}_{2} \mathrm{O}$. Each sample had 3 replicates. The cycle conditions were as follows: $95^{\circ} \mathrm{C}$ for $30 \mathrm{sec}$, 40 cycles at $95^{\circ} \mathrm{C}$ for $5 \mathrm{sec}$ and $60^{\circ} \mathrm{C}$ for $20 \mathrm{sec}$. The relative expression of miR-138 was calculated by the $2^{-\Delta \Delta \mathrm{Cq}}$ method compared with U6 (17).

ISG15 detection by RT-qPCR. The SYBR Green RT-qPCR Kit (Kapa Biosystems, Inc., Wilmington, MA, USA) was used to detect the expression of ISG15 in different specimens with GAPDH as an internal reference. The primers for ISG15 were forward 5'-GCGCAGATCACCCAGAAGAT-3' and reverse 5'-GTTCGTCGCATTTGTCCACC-3'. The reaction system included $10 \mu \mathrm{l}$ SYBR EX Taq-Mix, $0.5 \mu \mathrm{l}$ forward primer, $0.5 \mu \mathrm{l}$ reverse primer, $1 \mu \mathrm{l}$ cDNA template and $8 \mu \mathrm{l} \mathrm{ddH_{2 }} \mathrm{O}$. Each sample had 3 replicates. The cycling conditions were as follows: $95^{\circ} \mathrm{C}$ for $10 \mathrm{~min}, 25$ cycles at $95^{\circ} \mathrm{C}$ for $1 \mathrm{~min}, 60^{\circ} \mathrm{C}$ for $40 \mathrm{sec}, 72^{\circ} \mathrm{C}$ for $30 \mathrm{sec}$ and finally $72^{\circ} \mathrm{C}$ for $1 \mathrm{~min}$. The relative expression was calculated using the $2^{-\Delta \Delta \mathrm{Cq}}$ method (17).

Western blot analysis. A total of $50 \mathrm{mg}$ of each tissue was ground into a powder with liquid nitrogen, and lysed with radioimmunoprecipitation assay for $20 \mathrm{~min}$ at $4^{\circ} \mathrm{C}(50 \mathrm{mM}$ Tris-base (Sigma-Aldrich; Merck KGaA, Darmstadt, Germany), 1 mM EDTA, $150 \mathrm{mM} \mathrm{NaCl,} \mathrm{0.1 \%} \mathrm{SDS}$ (Sigma-Aldrich; Merck KGaA), 1\% TritonX-100, 1\% Sodium deoxycholate lysis buffer (Sigma-Aldrich; Merck KGaA). The lysate was centrifuged at $12,000 \mathrm{~g} / \mathrm{min}$ for $5 \mathrm{~min}$ at $4^{\circ} \mathrm{C}$. Proteins from transfected cells were collected via trypsin digestion (Beyotime Institute of Biotechnology). The protein concentration was detected using a bicinchoninic acid assay kit 
(Beyotime Institute of Biotechnology). A total of $50 \mu \mathrm{l}$ protein was mixed with an equal volume of $2 \mathrm{X}$ SDS loading buffer and boiled at $100^{\circ} \mathrm{C}$ for $5 \mathrm{~min}$. The proteins ( $2 \mu \mathrm{g}$ per lane) were separated by $10 \%$ SDS-PAGE (100 V constant voltage) and transferred to polyvinylidene fluoride membranes $(300 \mathrm{~mA}$ constant current at $4^{\circ} \mathrm{C}$ ). The membrane then was blocked with 5\% non-fat milk in TBS-Tween 20 (TBST) buffer for $1 \mathrm{~h}$ at room temperature. Then, the primary rabbit anti-human ISG15 (ab92345; 1:1,000) and rabbit anti-human GAPDH antibodies (ab204481; 1:2,000) were added and incubated overnight at $4^{\circ} \mathrm{C}$. Following washing with TBST 3 times, the secondary horseradish peroxidase-conjugated goat anti-rabbit antibody (ab6721; 1:1,000) was added and incubated for $1 \mathrm{~h}$ at room temperature. All the antibodies were supplied by Abcam (Cambridge, MA, USA). Finally, after washing with TBST for 3 times, the membrane was developed via enhanced chemiluminescence plus reagent (EMD Millipore, Billerca, MA, USA). The developed film was scanned and quantified using Image Lab 4.0 software (Bio-Rad Laboratories, Inc., Hercules, CA, USA). GAPDH was used as an internal control to calculate the relative expression of ISG15. The experiment was repeated three times.

Cell migration assay. Migration assays were performed using a Transwell chamber (Corning Incorporated, Corning, NY, USA). Transfected cells of the miR-138, mock and control groups were collected using trypsin and re-suspended in DMEM containing $0.1 \%$ BSA to give a concentration of $5 \times 10^{5}$ cells $/ \mathrm{ml}$. A total of $200 \mu \mathrm{l}$ cell medium, containing $1 \times 10^{5}$ cells, was seeded into the upper chamber and the bottom chamber was incubated with $750 \mu 1$ medium containing $20 \%$ FBS. Cells were cultured at $37^{\circ} \mathrm{C}$ for $4 \mathrm{~h}$ and cells in the upper chamber were scratched with a cotton swab. The cells in the lower chamber were fixed with formaldehyde at $22^{\circ} \mathrm{C}$ for $15 \mathrm{~min}$ and stained using $0.1 \%$ crystal violet at $22^{\circ} \mathrm{C}$ for $20 \mathrm{~min}$. Cells were then counted under a light microscope, and 3 fields were observed in each group. At 24, 48 and $72 \mathrm{~h}$ post-transfection, the three groups of CAL27 and SCC-15 cells (control, miR-138 and Neg-miR-138 groups) were mixed with $20 \mu \mathrm{l}$ MTT solution (Beyotime Institute of Biotechnology). Cells were incubated for $4 \mathrm{~h}$ at $37^{\circ} \mathrm{C}$ and the culture supernatant was subsequently discarded. A further $150 \mu \mathrm{l}$ MTT solution was added and the absorbance of CAL27 and SCC-15 cells was measured at $492 \mathrm{~nm}$. The experiment was repeated three times.

Cell invasion assay. The invasion of CAL27 and SCC-15 cell lines was analyzed using a Transwell chamber (BD Biosciences, Franklin Lakes, NJ, USA). In the Transwell chambers, $500 \mu \mathrm{l}$ serum-free DMEM was added and placed at room temperature for $1 \mathrm{~h}$ for matrigel hydration. The lower chamber was incubated with $750 \mu$ l DMEM containing $20 \%$ FBS. The transfected cells of the miR-138, mock and control groups were re-suspended to give a concentration of $4 \times 10^{5}$ cells $/ \mathrm{ml}$. A total of $500 \mu \mathrm{l}$ cell suspension was added to each chamber and subsequently cultured for $18 \mathrm{~h}$ at $37^{\circ} \mathrm{C}$ in an atmosphere containing $5 \% \mathrm{CO}_{2}$. Cells in the upper chamber were scratched with a cotton swab and cells in the lower chamber were fixed with $100 \%$ formaldehyde for $5 \mathrm{~min}$ at $22^{\circ} \mathrm{C}$ and stained with $0.1 \%$ crystal violet for $5 \mathrm{~min}$ at $22^{\circ} \mathrm{C}$.
The number of cells was subsequently counted under a light microscope. The experiment was repeated three times.

Statistical analysis. Data were analyzed using SPSS, version 16.0 (SPSS, Inc., Chicago, IL, USA). All data are expressed as the mean \pm standard deviation, and differences were determined using two-tailed Student's t-tests. $\mathrm{P}<0.05$ was considered to indicated a statistically significant difference.

\section{Results}

ISG15 expression in OSCC tissues. To investigate the role of ISG15 in OSCC tissues, RT-qPCR was used to detect the expression of ISG15 mRNA. The results revealed that ISG15 expression was significantly upregulated in OSCC tumor tissues compared with pericancerous tissues ( $\mathrm{P}<0.05$; Fig. 1A).

Western blot analysis was used to evaluate the ISG15 protein expression in OSCC tissues and associated pericancerous tissues. Expression of ISG15 protein was significantly higher in OSCC tissues compared with pericancerous tissues $(\mathrm{P}<0.05$; Fig. 1B), consistent with mRNA expression. These findings indicate that ISG15 expression is modulated during the development and progression of OSCC.

Bioinformatics prediction and miR-138 expression in OSCC. TargetScan was used to predict potential miRNAs for complementary binding to the ISG15 3'UTR (Fig. 2A). Based on these results combined with a literature review, miR-138 was selected for the present study.

To further investigate the mechanisms of miR-138 in OSCC tissues, RT-qPCR was used to detect miR-138 expression, which was significantly downregulated in OSCC tumor tissues compared with pericancerous tissues $(\mathrm{P}<0.05$; Fig. $2 \mathrm{~B})$. These results suggest that miR-138 participated in the regulation of OSCC.

miR-138 inhibits ISG15 expression. To investigate how miR-138 regulates the expression of ISG15, a pGCMV/ EGFP/miR-138 overexpression plasmid was constructed. The liposome method was used to transfect CAL27 and SCC-15 cell lines. At $48 \mathrm{~h}$ post-transfection, transfection efficiency was determined by validating miR-138 expression. miR-138 expression was significantly higher in the miR-138 group compared with mock and control groups, in both cell lines $(\mathrm{P}<0.05$; Fig. 3A). RT-qPCR and western blot analysis were used to detect the expression of ISG15 mRNA and protein in transfected cells. The results demonstrated that miR-138 overexpression is able to significantly decrease the expression of IGS15 mRNA protein, compared with the mock and control groups, in both cell lines $(\mathrm{P}<0.05$; Fig. $3 \mathrm{~B}$ and $\mathrm{C})$. These findings indicated that miR-138 was able to inhibit the transcription of ISG15 mRNA and translation of ISG15 protein.

miR-138 inhibits invasion, migration and proliferation of CAL27 and SCC-15 cells. Matrigel and Transwell chambers were used to investigate the invasion and migration of differently transfected cells. It was demonstrated that miR-138 overexpression significantly repressed the migration and invasion abilities of CAL27 and SCC-15 cells compared with mock and control groups $(\mathrm{P}<0.05$; Fig. $4 \mathrm{~A}$ and $\mathrm{B})$. These 
A

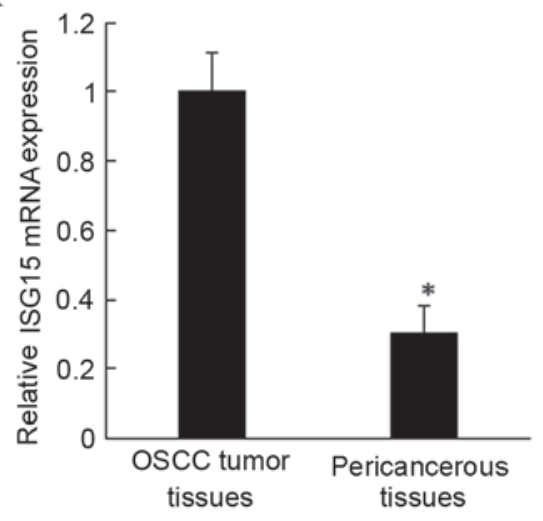

$\mathrm{B}$

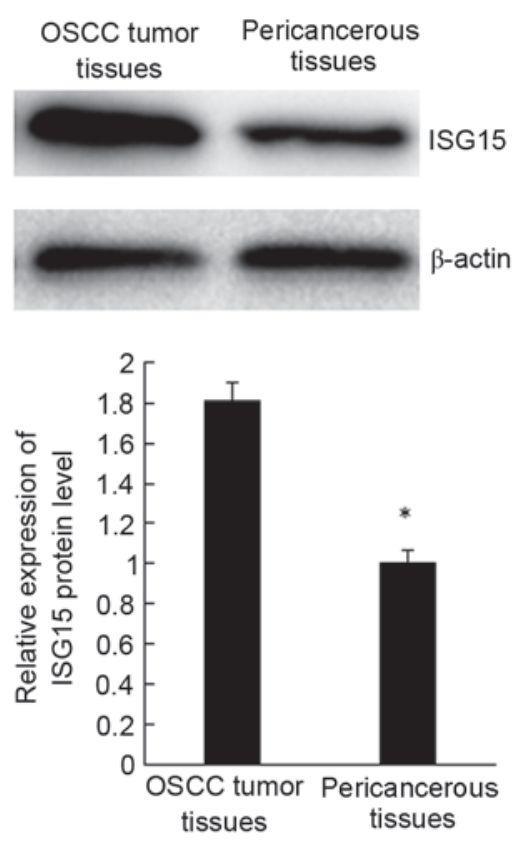

Figure 1. Expression of ISG15 in OSCC tissues. (A) ISG15 mRNA was increased in OSCC tumor tissues compared with pericancerous tissues by reverse transcription-quantitative polymerase chain reaction. (B) ISG15 protein was increased in OSCC tumor tissues compared with pericancerous tissues by western blot analysis. "P<0.05 vs. pericancerous tissues. ISG15, interferon-stimulated gene 15; OSCC, oral squamous cell carcinoma.

A

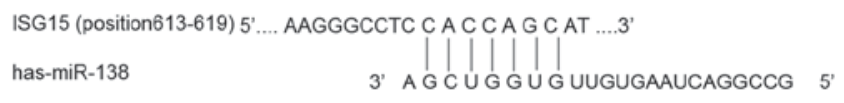

$\mathrm{B}$

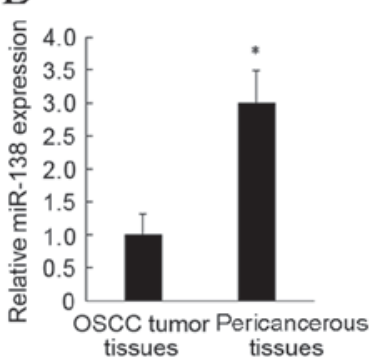

Figure 2. ISG15 is a direct target gene of miR-138. (A) miR-138 seed sequence and the binding sites on ISG15 3'-untranslated region. (B) miR-138 was decreased in OSCC tumor tissues compared with pericancerous tissues. ${ }^{*} \mathrm{P}<0.05$ vs. pericancerous tissues. ISG15, interferon-stimulated gene 15 ; miR, microRNA; OSCC, oral squamous cell carcinoma.

findings indicate that miR-138 was able to inhibition roles on OSCC cell movement.

MTT assay was used to detect the changes in proliferation of CAL27 and SCC-15 cells. Proliferation activity was significantly lower in the miR-138 group than in mock and control groups $(\mathrm{P}<0.05$; Fig. $4 \mathrm{C})$, which indicates that miR-138 is able to repress the proliferation of CAL27 and SCC-15 cell lines.

\section{Discussion}

ISG15 is a small molecular weight protein whose expression is induced by interferon (18). It was first identified as an ubiquitin-like modified protein and was named ubiquitin cross-reactive protein as its structure was similar to ubiquitin (18). Ubiquitin is a highly conserved small molecule that exists widely in eukaryotes and participates in protein degradation via protein modification in an enzyme cascade reaction (19). Similarly, ISG15 is involved in the regulation of various biological processes via binding to target proteins through a series of enzyme reactions to bind to the target protein $(20,21)$. At present, >200 ISG15 target proteins have been identified in virus-infected cells or tumor cells, which suggests that ISG15 serves important roles in immune regulation and tumor development $(21,22)$. It has previously been demonstrated that ISG15 is differentially expressed in different tumor cells and different cell lines from same histologic origin (15). In the present study, RT-qPCR and western blot analysis were used to detect ISG15 expression in OSCC tumor tissues and pericancerous tissues. The results demonstrated that that the expression of ISG15 mRNA and protein was significantly higher in tumors than in adjacent control tissues. Using bioinformatics, it was predicted that miR-138 was able to complementarily bind to the ISG15 3'UTR. In the present study, it was demonstrated that miR-138 expression was significantly lower in cancer tissues than in adjacent tissues, which indicates that ISG15 expression is associated with miR-138 expression.

miRNA broadly participates in the regulation of protein translation and mRNA stability (23). In order to investigate this further, a vector was constructed to induce miR-138 overexpression in cells. The CAL27 and SCC-15 cells were chosen for the present study and successfully transfected with the vector. It was demonstrated that miR-138 overexpression was able to repress ISG15 mRNA and protein levels, which indicates that miR-138 may regulate ISG15 expression via directly binding to the 3'UTR of ISG15. Proliferation, 
A
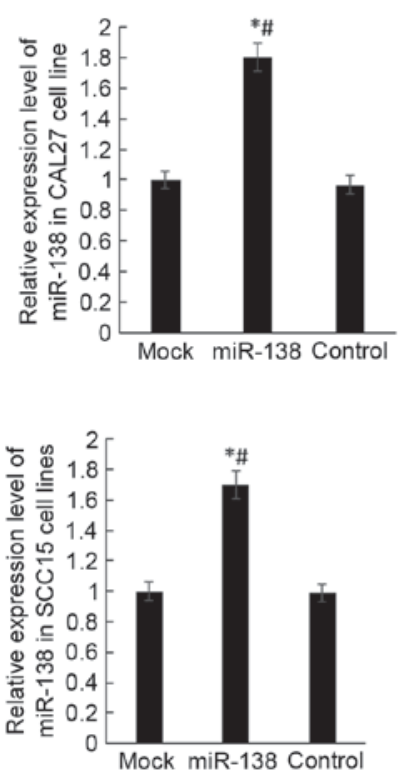

$\mathrm{B}$
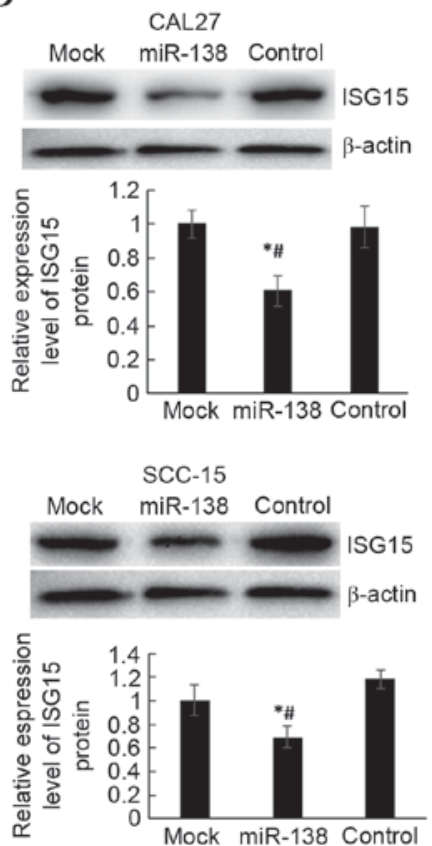

$\mathrm{C}$
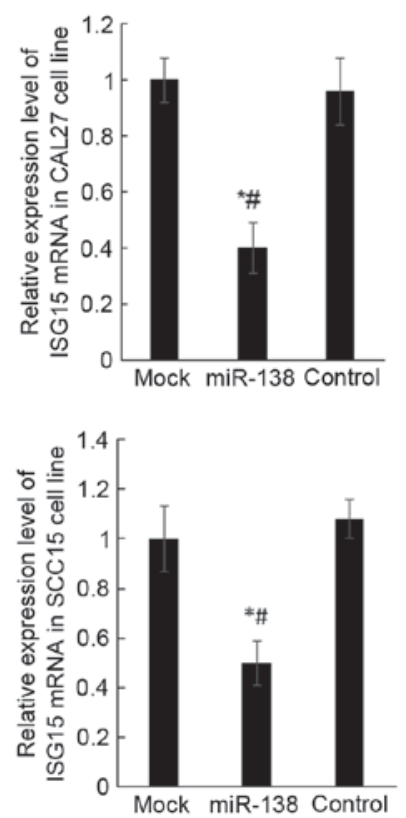

Figure 3. miR-138 inhibits ISG15 expression. (A) RT-qPCR to detect miR-138 expression in miR-138 group, mock group and control group following transfection of miR-138. (B) Western blot analysis was performed to detect ISG15 protein expression following transfection of miR-138. (C) RT-qPCR analysis was performed to detect ISG15 mRNA expression following transfection of miR-138. ${ }^{*} \mathrm{P}<0.05$ vs. mock group, ${ }^{\sharp} \mathrm{P}<0.05$ vs. control group. miR, microRNA; ISG15, interferon-stimulated gene 15; RT-qPCR; reverse transcription-quantitative polymerase chain reaction.

A
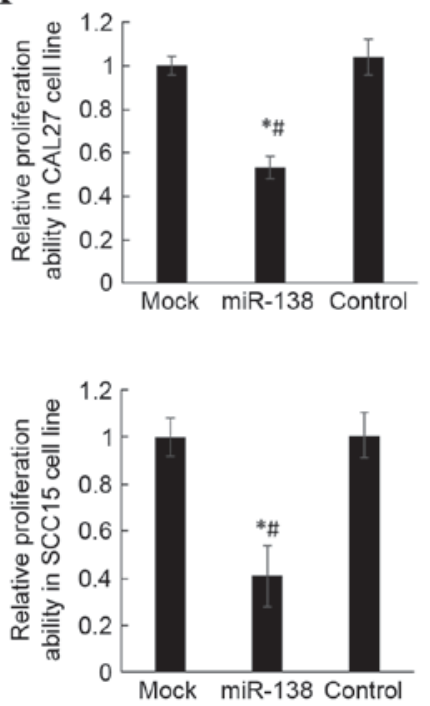

$\mathrm{B}$
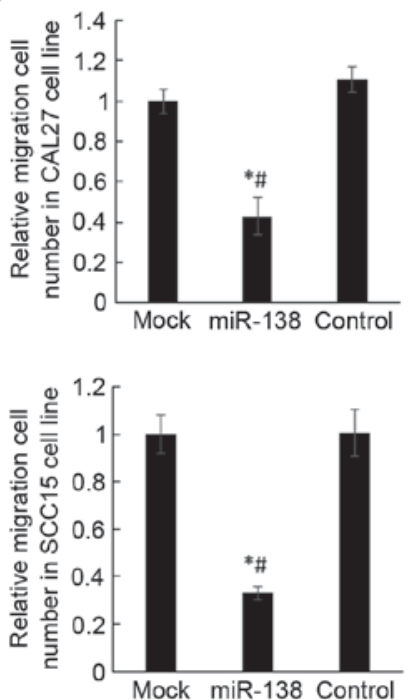

$\mathrm{C}$
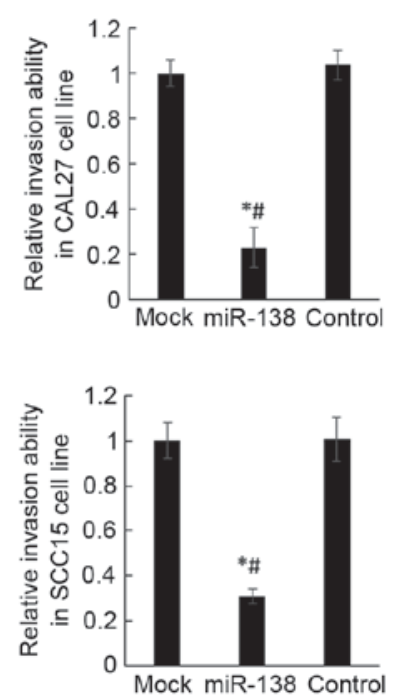

Figure 4. miR-138 inhibits the invasion and migration of CAL27 and SCC-15 cell lines. (A) Matrigel invasion chambers were used to analyze the migration of CAL27 and SCC-15 cell lines. (B) Transwell assay to analyze the invasion of CAL27 and SCC-15 cell lines. (C) The MTT method was applied to detect the proliferation of CAL27 and SCC-15 cell lines. ${ }^{*} \mathrm{P}<0.05$ vs. mock group, ${ }^{~} \mathrm{P}<0.05$ vs. control group. miR, microRNA.

migration and invasion of CAL27 and SCC-15 miR-138 overexpression cells were assessed using MTT and Transwell assays. The results demonstrated that miR-138 decreased invasion and migration capability in CAL27 and SCC-15 cell lines and also induced a decrease in proliferation. Previous results have indicated that overexpression of ISG15 decreases the expression of poly-ubiquitinated proteins, which negatively regulates the ubiquitin pathway and poly-ubiquitin protein level (13). The level of poly-ubiquitination is a key factor to degrade target protein by proteasome (24). ISG15 is able to regulate the invasion and migration of tumor through ubiquitin induced protein modification (25). In conclusion, the results of the present study suggest that miR-138 may be able to regulate the biological processes of OSCC via repressing ISG15 expression. MiR-138 may serve a role by regulating the upstream factors in the ubiquitin-proteasome pathway. 
miR-138 may have potential applications as a novel biomarker for the early diagnosis and prognosis of OSCC.

\section{Acknowledgements}

The present study was supported by the Applied Basic Research Projects in Sichuan Province (grant no. 2013JY0126) and the Science \& Technology Department of Sichuan Province (grant no. 14JC0054).

\section{References}

1. Van Zyl A and Bunn BK: Clinical features of oral cancer SADJ 67: 566-569, 2012.

2. Williams HK: Molecular pathogenesis of oral squamous carcinoma. Mol Pathol 53: 165-172, 2000.

3. Lagos-Quintana M, Rauhut R, Lendeckel W and Tuschl T: Identification of novel genes coding for small expressed RNAs. Science 294: 853-858, 2001.

4. Cai Y, Yu X, Hu S and Yu J: A brief review on the mechanisms of miRNA regulation. Genomics Proteomics Bioinformatics 7: 147-154, 2009.

5. Kong YW, Ferland-McCollough D, Jackson TJ and Bushell M: microRNAs in cancer management. Lancet Oncol 13: e249-e258, 2012.

6. Lopez-Camarillo C, Marchat LA, Arechaga-Ocampo E, Perez-Plasencia C, Del Moral-Hernandez O, Castaneda-Ortiz EJ and Rodriguez-Cuevas S: MetastamiRs: Non-coding microRNAs driving cancer invasion and metastasis. Int J Mol Sci 13: 1347-1379, 2012.

7. Calin GA and Croce CM: MicroRNA signatures in human cancers. Nat Rev Cancer 6: 857-866, 2006.

8. Liu X, Lv XB, Wang XP, Sang Y, Xu S, Hu K, Wu M, Liang Y, Liu P, Tang J, et al: MiR-138 suppressed nasopharyngeal carcinoma growth and tumorigenesis by targeting the CCND1 oncogene. Cell Cycle 11: 2495-2506, 2012.

9. Wang W, Zhao LJ, Tan YX, Ren H and Qi ZT: MiR-138 induces cell cycle arrest by targeting cyclin D3 in hepatocellular carcinoma. Carcinogenesis 33: 1113-1120, 2012.

10. Yeh YM, Chuang CM, Chao KC and Wang LH: MicroRNA-138 suppresses ovarian cancer cell invasion and metastasis by targeting SOX4 and HIF-l $\alpha$. Int J Cancer 133: 867-878, 2013.

11. Glickman $\mathrm{MH}$ and Ciechanover A: The ubiquitin-proteasome proteolytic pathway: Destruction for the sake of construction. Physiol Rev 82: 373-428, 2002.
12. Friedman $\mathrm{J}$ and Xue D: To live or die by the sword: The regulation of apoptosis by the proteasome. Dev Cell 6: 460-461, 2004.

13. Desai SD, Haas AL, Wood LM, Tsai YC, Pestka S, Rubin EH, Saleem A, Nur-E-Kamal A and Liu LF: Elevated expression of ISG15 in tumor cells interferes with the ubiquitin/26S proteasome pathway. Cancer Res 66: 921-928, 2006.

14. Sato Y, Kamura T, Shirata N, Murata T, Kudoh A, Iwahori S, Nakayama S, Isomura $H$, Nishiyama $Y$ and Tsurumi $T$ : Degradation of phosphorylated P53 by viral protein-ESC E3 ligase complex. PLoS Pathog 5: e1000530, 2009.

15. Andersen JB, Aaboe M, Borden EC, Goloubeva OG, Hassel BA and Orntoft TF: Stage-associated overexpression of the ubiquitin-like protein, ISG15, in bladder cancer. Br J Cancer 94: 1465-1471, 2006.

16. Puissant $C$ and Houdebine LM: An improvement of the single-step method of RNA isolation by acid guanidinium thiocyanate-phenol-chloroform extraction. Biotechniques 8: $148-149,1990$.

17. Livak KJ and Schmittgen TD: Analysis of relative gene expression data using real-tie quantitative PCR and the 2(-Delta Delta C(T)) method. Methods 25: 402-408, 2001.

18. Reich N, Evans B, Levy D, Fahey D, Knight E Jr and Darnell JE Jr: Interferon-induced transcription of a gene encoding a $15-\mathrm{kDa}$ protein depends on an upstream enhancer element. Proc Natl Acad Sci USA 84: 6394-6398, 1987.

19. Husnjak K and Dikic I: Ubiquitin-binding proteins: Decoders of ubiquitin-mediated cellular functions. Annu Rev Biochem 81: 291-322, 2012.

20. Zhao C, Denison C, Huibregtse JM, Gygi S and Krug RM: Human ISG15 conjugation targets both IFN-induced and constitutively expressed proteins functioning in diverse cellular pathways. Proc Natl Acad Sci USA 102: 10200-10205, 2005.

21. Andersen JB and Hassel BA: The interferon regulated ubiquitin-like protein, ISG15, in tumorigenesis: Friend or foe? Cytokine Growth Factor Rev 17: 411-421, 2006.

22. Jeon YJ, Yoo HM and Chung CH: ISG15 and immune diseases. Biochim Biophys Acta 1802: 485-496, 2010.

23. Huang Y, Shen XJ, Zou Q, Wang SP, Tang SM and Zhang GZ: Biological functions of microRNAs: A review. J Physiol Biochem 67: 129-139, 2011.

24. Krämer OH, Zhu P, Ostendorff HP, Golebiewski M, Tiefenbach J, Peters MA, Brill B, Groner B, Bach I, Heinzel T and Göttlicher M: The histone deacetylase inhibitor valproic acid selectively induces proteasomal degradation of HDAC2. EMBO J 22: 3411-3420, 2003

25. Desai SD, Reed RE, Burks J, Wood LM, Pullikuth AK, Haas AL, Liu LF, Breslin JW, Meiners S and Sankar S: ISG15 disrupts cytoskeletal architecture and promotes motility in human breast cancer cells. Exp Biol Med (Maywood) 237: 38-49. 2012. 